\title{
Unilateral Synchronous Multiple Kidney Tumors Managed by Laparoscopic Partial Nephrectomy: Five-year Follow-up
}

\author{
Mehmet Necmettin Mercimek1, Latif Mustafa Ozbek2 and Ender Ozden³ \\ 1Department of Urology, Samsun Liv Hospital, 55020, Ilkadim, Samsun, Turkey \\ ${ }^{2}$ Department of Urology, Igdir State Hospital, 76000, Igdir, Turkey \\ ${ }^{3}$ Department of Urology, Faculty of Medicine, Ondokuz Mayis University, 55210, Kurupelit, Samsun, Turkey
}

\begin{abstract}
Unilateral synchronous multifocal renal tumors are rare. Due to the limited data in the literature and challenges in the technique, there is still doubt on the application of laparoscopic partial nephrectomy (LPN) for the management of such tumors. Herein, we report a 36-year male patient presenting with right-sided flank pain and microscopic hematuria. Abdominal computed tomography (CT) revealed five solid masses, the largest of which was $27 \times 18 \mathrm{~mm}$. The patient underwent LPN and the largest mass was resected with the control of segmental artery of the lower pole of the right kidney. The remaining four masses were resected by zero-ischemia technique. Final pathology revealed renal cell carcinoma in all masses. Postoperative period was uneventful. No recurrence was detected during a 5-year follow-up.
\end{abstract}

Key Words: Kidney tumor, Renal cell carcinoma, Laparoscopic partial nephrectomy.

How to cite this article: Mercimek MN, Ozbek LM, Ozden E. Unilateral synchronous multiple kidney tumors managed by laparoscopic partial nephrectomy: five-year follow-up. J Coll Physicians Surg Pak 2019; 29 (Supplement 2):S157-S159.

\section{INTRODUCTION}

The presence of multifocal disease in patients with renal tumors smaller than $5 \mathrm{~cm}$ has been reported to be between $5 \%$ and $25 \%$ in the literature. Besides, unilateral synchronous multifocal renal masses (UMRM) are very rare and occur in $0.5-5.4 \%$ of all renal tumor patients.1,2 A limited amount of data on UMRM causes ongoing debates on how these patients should be treated. Laparoscopic nephron sparing surgery is still rarely performed due to technical difficulty and concern about oncological outcomes. Hence, radical nephrectomy (RN) has been widely used to maximise oncological benefits despite the deterioration of renal function in patients with multiple synchronous tumors.

Herein, we aimed to present laparoscopic management and follow-up results of a patient who has synchronous multiple renal tumors in the right kidney.

\section{CASE REPORT}

A 36-year male patient was evaluated for right-sided pain in another hospital. Upon detection of microscopic hematuria, and leukocytes, 30/HPF (high power field), on urinalysis, abdominal ultrasonography was performed and a $3 \mathrm{~cm}$ mass was detected in the lower pole of the

Correspondence to: Mehmet Necmettin Mercimek,

Department of Urology, Samsun Liv Hospital, 55020, Ilkadim,

Samsun, Turkey

E-mail:mehmet.mercimek@istinye.edu.tr

Received: May 09, 2019; Revised: July 16, 2019;

Accepted: July 27, 2019 right kidney. The physical examination of the patient was normal. He gave history of smoking that he used to take 1 pack a day for 10 years and took alcohol regularly. Contrast-enhanced CT was performed, which revealed a total of five tumors in the right kidney. The largest of the tumors was located in the inferior pole of the right kidney with exophytic features, and $27 \times 18 \mathrm{~mm}$ in size. The localisation and dimensions of other four tumors are shown in Table I and Figure 1. Laparoscopic partial nephrectomy (LPN) was proposed to the patient and informed consent was obtained. Four trocars were used: 1 for camera, 2 working trocars, and 1 for assistant. During renal hilum dissection, it was seen that right renal artery was divided into two segmental arteries at the lateral side of the vena cava. Both segmental arteries were released and the segmental artery of the inferior pole was isolated with vascular silicon tapes. Then, renal vein and ureter were dissected and then isolated. The kidney was mobilised from the surrounding tissues completely. Laparoscopic ultrasound was used to detect the tumors and determine the surgical margins. Monopolar hook was used to score the surgical margins. Four small tumors were completely resected by cold scissors with non-ischemic technique; remaining renal parenchyma was sutured in two layers, supported with hem-o-lock clips. The largest tumor located at the inferior pole was resected with the control of segmental artery by laparoscopic bulldog clamp. After the removal of the tumor, the lower pole was repaired in a similar fashion. The duration of surgery and warm ischemia time were 170 and 15 minutes, respectively. The histopathological evaluation of all the tumors revealed 
Table I: Characteristics of individual tumors

\begin{tabular}{l|c|l|l|l}
\hline Number & $\begin{array}{c}\text { Size } \\
(\mathrm{mm})\end{array}$ & Localisation & $\begin{array}{l}\text { Dissection } \\
\text { technique }\end{array}$ & Pathology \\
\hline $1^{\text {st }}$ & 10 & Middle pole lateral & Zero-ischemia & CCRCC \\
\hline $2^{\text {nd }}$ & 10 & Lower pole medial & Zero-ischemia & CCRCC \\
\hline $3^{\text {rd }}$ & 13 & Lower pole lateral & Zero-ischemia & CCRCC \\
\hline $4^{\text {th }}$ & 14 & Upper pole-posterior & Zero-ischemia & CCRCC \\
\hline $5^{\text {th }}$ & 27 & Lower pole & Segmental-artery & CCRCC \\
\hline
\end{tabular}

CCRCC = Clear cell renal cell carcinoma

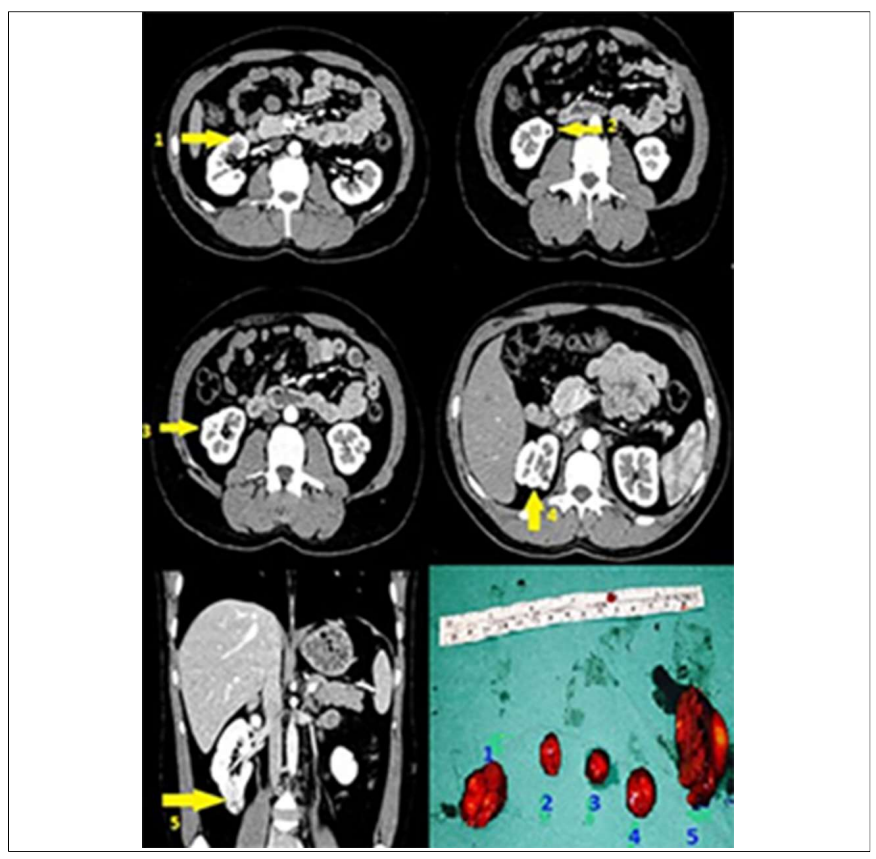

Figure 1: Preoperative CT images and postoperative macroscopic features of right renal tumors. Arrows and numbers 1 to 5 were used to mark tumors on the CT images and the back table.

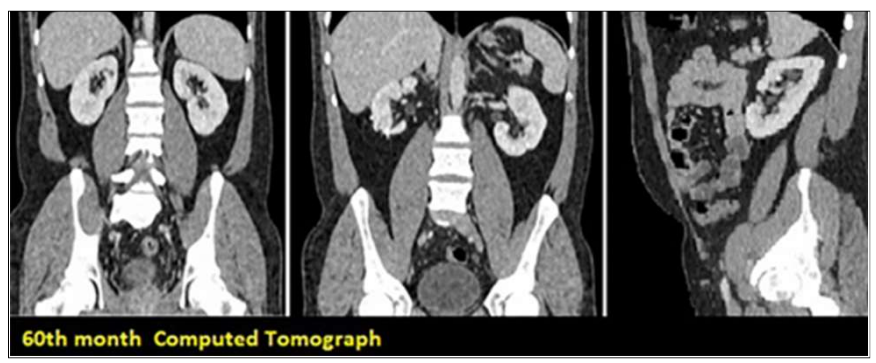

Figure 2: No recurrence was detected during the follow-up period of 5 years.

clear renal cell carcinoma, Fuhrman grade 2, and surgical margins were negative for all tumors. The patient was followed-up for 5 years and no recurrence was detected. The estimated glomerular filtration rates of the patient preoperatively and on the last visit were 115 and 93 $\mathrm{mL} / \mathrm{min} / 1.73 \mathrm{~m} 2$, respectively. Five-year follow-up CT images are shown in Figure 2.

\section{DISCUSSION}

LPN is recommended for CT1 renal masses to reduce cardiovascular morbidity and prevent chronic renal failure. ${ }^{3}$ Simhan et al. published the results of the largest series in literature of patients with UMRM, who were managed by PN. In this paper, 76 patients, three of which were managed by laparoscopy, had a total of 241 UMRM, underwent nephron sparing surgery. The mean tumor size was $2 \mathrm{~cm}$ and there was a median of 3 tumors per patient. The median follow-up was 24 months. In this paper, although the overall demographic data and outcomes of patients have been provided, the outcomes of patients who underwent LPN were not discussed separately. As a result, they stated that PN may be performed in patients with UMRM with acceptable oncological and functional results. ${ }^{1}$ In another study comparing partial and $\mathrm{RN}$ results of patients with UMRM, it is mentioned that there was no significant difference in cancer-specific survival. ${ }^{4}$

Since LPN is technically difficult in patients with complex renal tumors compared to $\mathrm{RN}$, it is not widely preferred. ${ }^{5}$ However, PN with minimally invasive techniques is recommended in complex and large tumors. ${ }^{6}$

Curcio et al. presented a case report of a patient with four tumors in the same kidney managed laparoscopically. Surgery was performed in two stages. According to RENAL score of the tumors, 2 of them were resected without vascular control. The remaining 2 tumors were resected after vascular control. The histopathological examination revealed that all tumors were papillary cancer with negative tumor margins. ${ }^{7}$

In the present case report, we performed resection of the largest tumor, localised to the lower pole of the right kidney after segmental artery control. The remaining four tumors were resected by the non-ischemic technique. Final pathology revealed clear renal cell carcinoma with negative tumor margins in all tumors.

In conclusion, LPN for multiple kidney tumors in selective patients may provide significant advantages in terms of preservation of renal functions and oncological results.

\section{PATIENT'S CONSENT:}

Informed consent was obtained from the patient after obtaining approval from the Ethics Committee of Ondokuz Mayis University (OMU KAEK approval No. 2019/151).

\section{CONFLICT OF INTEREST:}

Authors declared no conflict of interest.

\section{AUTHORS' CONTRIBUTION:}

MNM: Conception and design, acquisition of data, drafting of manuscript, and critical revision of the manuscript. LMO: Conception and design, drafting of manuscript.

EO: Acquisition of data, critical revision of the manuscript, supervision.

\section{REFERENCES}

1. Simhan J, Canter DJ, Sterious SN, Smaldone MC, Tsai KJ, Li T, et al. Pathological concordance and surgical outcomes of sporadic synchronous unilateral multifocal renal masses treated with partial nephrectomy. J Urol 2013; 189:43-7. 
2. Alhusban M, Alhamss S, Alzumaili B, Al-Daghmin A. Ipsilateral synchronous clear and papillary renal cell carcinoma: A case report and review of the literature. Urol Case Rep 2018; 16: 110-3.

3. Campbell SC, Novick AC, Belldegrun A, Blute ML, Chow GK, Derweesh $\mathrm{IH}$, et al. Guidelines for management of the clinical T1 renal mass. J Urol 2009; 182:1271-9.

4. Krambeck A, Iwaszko M, Leibovich B, Cheville J, Frank I, Blute M. Long-term outcome of multiple ipsilateral renal tumours found at the time of planned nephron-sparing surgery. BJU Int 2008; 101:1375-9.
5. Kim SP, Shah ND, Weight CJ, Thompson RH, Moriarty JP, Shippee ND, et al. Contemporary trends in nephrectomy for renal cell carcinoma in the United States: Results from a population-based cohort. J Urol 2011; 186:1779-85.

6. Touijer K, Jacqmin D, Kavoussi LR, Montorsi F, Patard JJ, Rogers CG, et al. The expanding role of partial nephrectomy: A critical analysis of indications, results, and complications. Eur Urol 2010; 57:214-22.

7. Curcio L, Salama B, Pinto, DL, Ahouagi AC. Laparoscopic partial nephrectomy for multiple (four) tumors. Int Braz J Urol 2017; 43:567.

....综.... 